\title{
Soluble Factors Secreted by Endothelial Cells Allow for Productive and Latent HIV-1 Infection in Resting $\mathrm{CD}^{+} \mathrm{T}$ Cells
}

\author{
John Henry Morris III,' Tran Nguyen,, Abuoma Nwadike,, Mackenzie L. Geels, \\ Derrick L. Kamp, Bo Ram Kim, Jean D. Boyer, and Anding Shen ${ }^{1}$
}

\begin{abstract}
In vitro, it is difficult to infect resting $\mathrm{CD}^{+} \mathrm{T}$ cells with human immunodeficiency virus type 1 (HIV), but infections readily occur in vivo. Endothelial cells (ECs) interact with resting $\mathrm{CD}^{+} \mathrm{T}$ cells in vivo, and we found previously that EC stimulation leads to productive and latent $\mathrm{HIV}$ infection of resting $\mathrm{CD} 4^{+} \mathrm{T}$ cells. In this study, we further characterize the interactions between $\mathrm{EC}$ and resting $\mathrm{T}$ cells. We found that resting $\mathrm{CD} 4^{+} \mathrm{T}$ cells did not require direct contact with $\mathrm{EC}$ for productive and/or latent infection to occur, indicating the involvement of soluble factors. Among 30 cytokines tested in a multiplex enzyme-linked immunosorbent assay (ELISA), we found that expressions for IL-6, IL-8, and CCL2 were much higher in EC-stimulated resting T cells than resting T cells cultured alone. IL- 6 was found to be the soluble factor responsible for inducing productive infection of resting T cells, although direct contact with EC had an added effect. However, none of the cytokines tested, IL-6, IL-8, or CCL2, induced additional latent infection in resting T cells, suggesting that unidentified cytokines were involved. Intracellular molecules MURR1, c-Jun N-terminal kinase (JNK), and glucose transporter-1 (GLUT1) were previously shown in blocking HIV infection of resting $\mathrm{CD}^{+} \mathrm{T}$ cells. We found that the concentrations of these proteins were not significantly different in resting $\mathrm{T}$ cells before and after stimulation by EC; therefore, they are not likely involved in EC stimulation of resting $\mathrm{CD}^{+} \mathrm{T}$ cells, and a new mechanism is yet to be identified.
\end{abstract}

Keywords: HIV, HIV/AIDS pathogenesis, T cells, viral reservoirs

\section{Introduction}

A MAJOR BARRIER to eradicating HIV is the latent reservoir for HIV-1 in resting $\mathrm{CD}^{+}{ }^{+} \mathrm{T}$ cells. This reservoir ensures viral persistence in infected patients, and its elimination could greatly advance HIV cure research.

Since the discovery of the reservoir in the 1990s, much has been learned about its size and turnover rates, ${ }^{1}$ the types of viruses in it, ${ }^{2}$ the preferred integration sites, ${ }^{3}$ and which stimuli reactivate the latent viruses. ${ }^{4}$ However, our understanding of how the latent reservoir is formed is still limited and relies mainly on in vitro infection studies. It is widely accepted that HIV can only effectively infect activated CD4 ${ }^{+}$ $\mathrm{T}$ cells, ${ }^{5-9}$ and in resting $\mathrm{T}$ cells infected in vitro, the virus enters the cell, but either cannot efficiently complete reverse transcription $^{8}$ or cannot integrate its complementary DNA (cDNA) into the host genome. ${ }^{10,11}$ The currently favored model of latent reservoir formation is that HIV cannot directly infect resting $\mathrm{CD} 4^{+} \mathrm{T}$ cells. Rather, activated $\mathrm{CD} 4^{+} \mathrm{T}$ cells are infected and then revert to a resting phenotype with integrated provirus to form the latent reservoir.

However, more recent in vivo and ex vivo studies showed that resting $\mathrm{CD}^{+} \mathrm{T}$ cells were productively infected in vivo, or can be infected directly ex vivo, ${ }^{12-18}$ especially in the context of lymphoid tissues. One of the studies found that resting $\mathrm{CD}^{+} \mathrm{T}$ cells support HIV replication in lymphoid tissue (tonsil) explants, whereas purified tonsillar resting $\mathrm{CD} 4^{+} \mathrm{T}$ cells did not support HIV replication. ${ }^{19}$ These studies suggest that the in vivo lymphoid tissue microenvironment plays a crucial role in inducing productive and possibly latent infection in resting $\mathrm{CD}^{+} \mathrm{T}$ cells; therefore, further investigation of the microenvironment and cell-to-cell interactions within those microenvironments is greatly needed.

Two studies by Choi et al. ${ }^{20,21}$ demonstrated that stimulation by endothelial cells (ECs) rendered resting memory $\mathrm{CD}^{+} \mathrm{T}$ cells permissive for productive HIV-1 infection. This suggested that ECs, which physiologically serve as antigen presenting cells to $\mathrm{T}$ cells, particularly in lymphoid

${ }^{1}$ Department of Biology, Calvin College, Grand Rapids, Michigan.

${ }^{2}$ Department of Pathology and Laboratory Medicine, University of Pennsylvania, Philadelphia, Pennsylvania. 
microenvironments, might play a significant role in infection of resting $\mathrm{CD}^{+} \mathrm{T}$ cells in vivo.

In our last study, we verified that upon EC stimulation, resting $\mathrm{CD}^{+} \mathrm{T}$ cells can be productively infected by HIV while remaining in a resting phenotype. We further demonstrated that EC stimulation can result in latent infection in resting $\mathrm{CD}^{+}{ }^{+} \mathrm{T}$ cells as well, although EC stimulation did not reactivate already latent HIV provirus from patient $\mathrm{T}$ cells. ${ }^{22}$ We also found that cell death was reduced in infected resting $\mathrm{CD}^{+} \mathrm{T}$ cells that were stimulated by EC compared to infected activated T cells. When the life span of infected cells is prolonged, there may be increased viral production and an increased chance of latency formation. Overall in the last study, we demonstrated that EC stimulation played a significant role in HIV infection of resting $\mathrm{CD} 4^{+} \mathrm{T}$ cells and latent reservoir formation; therefore, characterizing this stimulation process is important in understanding HIV latency and infection.

It was previously thought that cell-to-cell contact between resting $\mathrm{CD}^{+} \mathrm{T}$ cells and $\mathrm{EC}$ must be present to stimulate the resting cells and induce productive infection. ${ }^{20,21}$ The stimulation was thought to be dependent on MHC-II and CD58 found on EC. ${ }^{20,21}$ However, further investigation by our laboratory showed that EC did not need to express MHC-II to induce productive infection ${ }^{22}$ and CD58 was not sufficient in stimulation of $\mathrm{T}$ cells (unpublished data). These discoveries led to the present study on the effect of EC-secreted soluble factors in $\mathrm{T}$ cell stimulation.

In addition, various proteins were discovered to either block or allow HIV infection in resting $\mathrm{CD}^{+} \mathrm{T}$ cells. One of these proteins is c-Jun N-terminal kinase ( JNK), which is highly expressed in activated $\mathrm{CD} 4^{+} \mathrm{T}$ cells, but relatively absent in resting $\mathrm{CD}^{+} \mathrm{T}$ cells. HIV infection of resting $\mathrm{T}$ cells is believed to be blocked at the integration step. Phosphorylated JNK (p-JNK) phosphorylates and thus activates viral integrase, which enables completion of viral integration into the host genome. $^{23}$ Another protein that is known to affect HIV infection levels in $\mathrm{CD}^{+} \mathrm{T}$ cells is Murr1, a protein commonly known for its involvement in copper regulation. Murr1 was previously found to inhibit HIV growth in resting $\mathrm{CD}^{+} \mathrm{T}$ cells, by inhibiting nuclear factor (NF)- $\kappa \mathrm{B}$ activity. ${ }^{24}$ Finally, increased glucose transporter-1 (Glut1) expression and increased glucose uptake were found to be associated with increased HIV infection of $\mathrm{CD}^{+}{ }^{+} \mathrm{T}$ cells. ${ }^{25}$ In this study, we investigate whether these three intracellular factors are implicated in EC stimulation of resting $\mathrm{CD} 4^{+} \mathrm{T}$ cells.

\section{Materials and Methods}

\section{Virus production}

The procedure for creating the green fluorescence protein (GFP) reporter virus has been previously described. ${ }^{22}$ Briefly, the enhanced green fluorescence protein (eGFP or GFP) reporter virus was generated by cotransfecting HEK293T cells with a plasmid encoding NL43-dE-GFP and a plasmid encoding the HIV-1 envelope (pWE-CXCR4) using TrueFect (United BioSystems) at a 2:1 ratio (pNL43:pWE). Supernatants were collected after $72 \mathrm{~h}$ and filtered through a $0.22 \mu \mathrm{m}$ membrane to remove cell debris. Virus particles were pelleted using Lenti-X concentrator (Clontech Laboratories) by following the manufacturer's instructions and resuspended with $1 / 27$ of the original volume of RPMI $+10 \%$ FBS.

\section{Isolation of $T$ cells and $T$ cell activation in vitro}

Primary $\mathrm{T}$ cells were obtained by processing peripheral blood mononuclear cells (PBMC) from HIV-negative donors as described. ${ }^{22}$ Briefly, a Ficoll-Hypaque sugar gradient was used to extract PBMC, and a magnetic bead-negative depletion kit was used for isolating $\mathrm{CD}^{+}{ }^{+} \mathrm{T}$ cells (Miltenyi Microbeads). $\mathrm{T}$ cell activation through anti-CD3 and anti-CD28 antibodies (BD Biosciences) was also described previously. ${ }^{22}$

\section{Direct contact in vitro infection assay}

The procedure for the EC in vitro assay has been described previously. $^{22}$ Briefly, human umbilical vein endothelial cells (HUVECs or ECs) were purchased (PromoCell) and cultured with or without interferon gamma (IFN- $\gamma ; 50 \mathrm{ng} / \mathrm{ml}$; Invitrogen) for 3 days. IFN- $\gamma$ induces the expression of MHC-II on EC. $\mathrm{EC}^{+}$and $\mathrm{EC}^{-}$indicate treatment with or without IFN- $\gamma$, respectively. Resting $\mathrm{CD}^{+} \mathrm{T}$ cells were cultured with $\mathrm{EC}$ for 1 day before infection with a GFP reporter virus. All cultures were examined at the peak of their infection, which Shen et al. have shown to be 6-7 days after infection for resting cultures, and 3 days after infection for T cells activated with anti-CD3 and anti-CD28 antibodies, ${ }^{22}$ unless stated otherwise.

\section{Transwell in vitro infection assay}

A similar experimental procedure was used as mentioned in direct contact. ECs treated with or without IFN- $\gamma\left(\mathrm{EC}^{+/-}\right)$ were plated with $100 \%$ confluency on the bottom of a 24-well cell culture plate in $0.5 \mathrm{ml}$ of RPMI $+10 \% \mathrm{FBS}$, and $300 \mu \mathrm{L}$ of resting $\mathrm{CD}^{+} \mathrm{T}$ cells in the concentration of 1 million per $\mathrm{ml}$ was added in Corning Transwell Inserts (24-well inserts, polyester or polycarbonate, pore size of $0.4 \mu \mathrm{m}$; SigmaAldrich) that rested over the EC cultures. The cells incubated together for a day, and then the GFP reporter virus was added. Infection rates were examined 7 days postinfection by measuring the percent of GFP-positive cells. When transwell experiments were compared with direct contact setup, 48well plates were used in direct contact wells because they had similar diameter as the 24-well inserts.

\section{Detection of latent infections}

As described previously, ${ }^{22}$ to detect latent infection, infected T cells were sorted for GFP-negative cells on day 8 postinfection. GFP-negative cells were then cultured alone or activated with phorbol myristate acetate (PMA) and Ionomycin for 2 days along with the integrase inhibitor raltegravir to block any integration during activation. GFP expressions were then compared in cultures with or without activation.

\section{Removal of $T$ cells from EC stimulation}

Initial experimental setup is similar to that of the in vitro infection assays mentioned above. For direct contact removal experiments, after resting $\mathrm{CD}^{+}{ }^{+} \mathrm{T}$ cells (cocultured with EC) were infected, on day 1 and 3 postinfection, one third of the resting T cells were removed from the EC coculture and placed in a separate well. To ensure there were no residual EC in the removed resting $\mathrm{T}$ cells, the $\mathrm{T}$ cells were moved to another well after $4 \mathrm{~h}$ settling time (to let EC adhere). No additional media were added to either the separated wells or the original coculture wells. GFP expressions were measured in the separated 
wells and the original coculture wells on day 6 postinfection. For the transwell experiments, ECs $(+/-)$ were plated at the bottom of a 24-well cell culture plate in $200 \mu \mathrm{l}$ of RPMI $+10 \%$ FBS. Corning Transwell Inserts were placed above the EC cultures, and $100 \mu \mathrm{l}$ of resting $\mathrm{CD}^{+} \mathrm{T}$ cells was added at a concentration of 5 million per ml. The cells incubated for a day, and then $100 \mu \mathrm{l}$ GFP reporter virus was added. One day after infection, the virus and soluble factors were washed from the cell culture inserts by removing the inserts, placing them in an empty cell culture well, and allowing the media to drain for an hour. The media surrounding the ECs were also removed, and $1 \mathrm{ml}$ of fresh RPMI $+10 \%$ FBS was added. The cell culture inserts were then returned to their original wells (with EC on the bottom), and $70 \mu \mathrm{l}$ of resting T cells was removed from the cell culture inserts on days 1, 3, 5, and 7 postinfection and placed in a separate well containing $930 \mu \mathrm{l}$ of fresh RPMI + $10 \%$ FBS. On day 7 postinfection, GFP expressions were measured in the $\mathrm{T}$ cells from each of the wells removed at different times postinfection.

\section{Multiplex cytokine enzyme-linked immunosorbent assay}

Resting $\mathrm{CD}^{+}{ }^{+} \mathrm{T}$ cells isolated from HIV-negative donors were cultured alone, or with $\mathrm{EC}^{-}, \mathrm{EC}^{+}\left(\mathrm{EC}^{+}\right.$and $\mathrm{EC}^{-}$indicate treatment with or without IFN- $\gamma$, respectively), or MCF7 (human adenocarcinoma cell line, ATCC) for 6 days, and the supernatants were collected and stored at $-80^{\circ} \mathrm{C}$. The supernatants were analyzed using human cytokine magnetic 30plex panel kit (Millipore) at the Human Immunology Core at the University of Pennsylvania according to the manufacturer's protocol. Briefly, after washing the 96-well magnetic plate, $25 \mu \mathrm{l}$ of each sample, $25 \mu \mathrm{l}$ of assay buffer, and $25 \mu \mathrm{l}$ of beads were added per well. Following an overnight incubation on the shaker at 600 revolutions $/ \mathrm{min}$ at $4{ }^{\circ} \mathrm{C}$, the plate was washed and then incubated with $25 \mu \mathrm{l}$ of biotinylated detector antibody for $1 \mathrm{~h}$ and then with $25 \mu \mathrm{l}$ of Streptavidin-RPE for 30 min on the shaker in the dark. After two washes, the assay plate was transferred to the Bio-Plex Luminex 200 instrument for analysis. Cytokine concentrations were calculated using Bio-Plex Manager 5.0 software with a five parameter curvefitting algorithm applied for standard curve calculations. The levels of the cytokines present in $\mathrm{EC}^{+/-}$cocultured with resting $\mathrm{CD}^{+} \mathrm{T}$ cells were compared with those present in resting $\mathrm{T}$ cells alone or resting $\mathrm{T}$ cells cocultured with MCF7.

\section{$T$ cell stimulation with IL-6, IL-8, and CCL2}

Resting T cells were treated with recombinant human IL-6 (1 ng/ml; BioLegend), IL-8 (4 ng/ml; BioLegend), and CCL2 (MCP-1) $(50 \mathrm{ng} / \mathrm{ml}$; BioLegend) at concentrations several folds higher than those in EC cultures determined by the multiplex enzyme-linked immunosorbent assay (ELISA) to ensure potency of recombinant cytokines. After incubation with the cytokines for 1 day, the T cells were infected with the reporter virus. Cytokine levels were refreshed 1,3, and 5 days after infection, and the cells were examined for infection levels on the sixth day postinfection.

\section{Blocking IL-6 interactions with T cells}

ECs were plated and treated with LEAF Purified antihuman IL-6 antibody ( $1 \mathrm{mg} / \mathrm{ml}$; BioLegend) for $1 \mathrm{~h}$. Resting
$\mathrm{CD} 4^{+} \mathrm{T}$ cells were added in equal volumes to the $\mathrm{EC}$ allowing for contact, while anti-IL-6 antibodies were refreshed 1 and 3 days postinfection. Infection levels were measured 6 days after infection.

\section{Intracellular staining of MURR1 and p-JNK}

We compared levels of MURR1 and p-JNK expressed in resting cells, EC-stimulated resting cells, and cells activated by PMA (Sigma) and Ionomycin (Sigma) or phytohemagglutinin (PHA; Sigma). Approximately $2 \times 10^{5}$ cells were fixed and permeabilized using $4 \%$ formaldehyde and $0.1 \%$ Triton X-100 for MURR1 staining, or a Cytofix/Cytoperm kit (BD Biosciences) for p-JNK staining. After fixation and permeabilization, cells were stained in a $3 \%$ bovine serum albumin (BSA) solution by adding either the $2 \mu \mathrm{l}$ of $1: 10$ diluted anti-MURR1 Ab (Origene) or $2 \mu \mathrm{l}$ of the PhosphoSAPK/JNK (Thr183/Tyr185) (G9) Mouse mAb (Cell Signaling Technology). Cells were allowed to incubate at $4^{\circ} \mathrm{C}$ for $20 \mathrm{~min}$ in the dark and then were washed and resuspended in $100 \mu \mathrm{l}$ of $3 \%$ BSA solution $+6 \mu$ of $1: 27$ diluted anti-IgG1 antibody (BioLegend). Samples were incubated for another 20 min at $4^{\circ} \mathrm{C}$, in the dark, and were immediately analyzed on a BD FACSCalibur flow cytometer. To remove additional background, samples of each culture type were stained with the anti-IgG1 antibody alone, and that value was subtracted from experimental values to account for nonspecific binding.

\section{JNK western blot}

Approximately $3 \times 10^{5}$ cells were resuspended in a lysis buffer (62.5 mM Tris-HCl, pH 6.8, 25\% glycerol, $2 \%$ sodium dodecyl sulfate, and 0.01 Bromophenol Blue). The cells were then treated with Dithiothreitol $(50 \mathrm{mM})$, briefly boiled and loaded on a Novex $12 \%$ Tris-Glycine Gel $1.0 \mathrm{~mm}, 10$ well (Invitrogen). Samples were run at $125 \mathrm{~V}$ overnight and then transferred to a cellulose membrane using the XCell II Blot Module CE Mark (Invitrogen) in Odyssey Blocking Buffer (LI-COR Biosciences). JNK FL Antibody (Santa Cruz Biotechnology) was diluted at 1:2,000 and allowed to incubate with the membrane while shaking for $3 \mathrm{~h}$. The blot was rinsed in Tris-buffered saline with Tween (TBST), immersed IRDye 800CW Goat Anti-Rabbit IgG (LI-COR Biosciences), and allowed to incubate while shaking for $1 \mathrm{~h}$. The blot was again washed in TBST and immediately imaged on the Odyssey Infrared Imager (LI-COR Biosciences).

\section{GLUT1 antibody staining}

Approximately $1 \times 10^{5}$ cells were washed with phosphate buffered saline, and Mouse Monoclonal (IgG2b) to Human SLC2A1/GLUT-1 $(0.1 \mu \mathrm{g} / \mu \mathrm{l}$; LSBio) was added. Cells were then incubated for $20 \mathrm{~min}$ in the dark, rewashed, and incubated with APC/Cy7 goat anti-mouse IgG $(20 \mathrm{ng} / \mu \mathrm{l}$; BioLegend) for another $20 \mathrm{~min}$ in the dark. After a final wash, the cells were analyzed on a BD FACSCalibur flow cytometer using the CellQuest Pro program (Becton Dickinson).

\section{Results}

\section{Resting $C D 4^{+} T$ cells can be stimulated by EC without direct contact}

We previously demonstrated that direct contact with EC can stimulate resting $\mathrm{CD}^{+} \mathrm{T}$ cells for productive $\mathrm{HIV}$ 
infection while remaining in the resting phenotype. ${ }^{22}$ In this study, we first examined whether resting $\mathrm{CD} 4^{+} \mathrm{T}$ cells could be stimulated without direct contact, rather by soluble factors secreted by EC. Resting $\mathrm{CD}^{+} \mathrm{T}$ cells were isolated from HIVnegative donors and cocultured with $\mathrm{EC}^{+}$and $\mathrm{EC}^{-}$(previously treated with or without IFN- $\gamma$, respectively) in setups that allowed for direct contact or only soluble factor exchange, that is, in transwells. Treatment of IFN- $\gamma$ for 3 days induced expression of MHC-II on EC. To ensure the size of the wells in normal and transwell wells does not affect infection rates, resting $\mathrm{CD}^{+} \mathrm{T}$ cells were cultured alone in normal wells or in transwells to serve as controls. After 1 day of coculturing, $T$ cells were infected with the GFP reporter virus, and infection rates $\left(\% \mathrm{GFP}^{+}\right)$were examined on day 7 postinfection.

As seen in Figure 1, while resting $\mathrm{CD}^{+} \mathrm{T}$ cells cultured alone in normal wells or in transwells showed the same amount of infection, higher infection rates were observed in resting $\mathrm{T}$ cells stimulated by EC (+ and - ) in transwells compared to resting cells alone. When direct contact was allowed, $\mathrm{EC}^{+}$-stimulated $\mathrm{T}$ cells had substantially higher infection rates than those stimulated in transwells, while $\mathrm{EC}^{-}$ stimulation in direct contact resulted in just slightly more infection rates than stimulation in transwells.

This suggests that, while soluble factors only accounted for about half of the effect in $\mathrm{EC}^{+}$stimulation, they accounted for the majority of the effect of $\mathrm{EC}^{-}$stimulation. The data also show that when only soluble factor exchange was permitted, the infection rates of $\mathrm{EC}^{+}$- and $\mathrm{EC}^{-}$-stimulated $\mathrm{T}$ cells were similar, suggesting that similar soluble factors were involved in both $\mathrm{EC}^{+}$and $\mathrm{EC}^{-}$stimulations.

\section{Soluble factors secreted by EC can induce latent HIV infections in resting $\mathrm{CD} 4^{+} \mathrm{T}$ cells}

We have shown previously that stimulation by EC resulted in latent $\mathrm{HIV}$ infection of resting $\mathrm{CD}^{+}{ }^{+} \mathrm{T}$ cells, ${ }^{22}$ so we

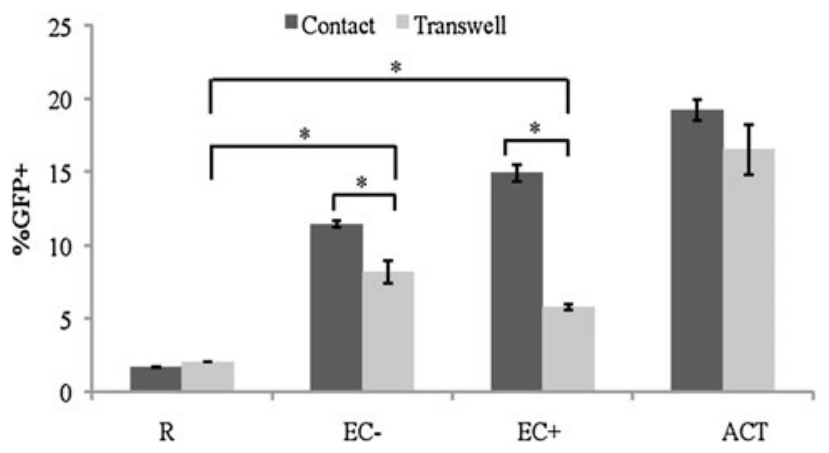

FIG. 1. Resting $\mathrm{CD} 4^{+} \mathrm{T}$ cells can be stimulated by EC without direct contact. Resting $\mathrm{T}$ cells were cultured alone, in direct contact with EC, or without direct contact, but in transwells with EC. $\mathrm{EC}^{+}$and $\mathrm{EC}^{-}$indicate treatment with or without IFN- $\gamma$, respectively. Activated T cells (AC) through $\mathrm{CD} 3$ and $\mathrm{CD} 28$ stimulations were included as a control. All T cells were infected with a HIV reporter virus expressing GFP 1 day after coculture, and the $\% \mathrm{GFP}^{+}$cells were measured on day 7 postinfection. Samples were taken in quadruplicates, and means \pm standard errors are plotted. Data shown are the representative of four independent experiments yielding similar results. ${ }^{*} p<.05$, Student $t$ test. EC, endothelial cell; GFP, green fluorescence protein; IFN- $\gamma$, interferon gamma. decided to test if soluble factors would also allow for latent infection. Resting $\mathrm{T}$ cells were cultured alone, activated with $\mathrm{CD} 3 / \mathrm{CD} 28$, or cultured with $\mathrm{EC}^{-}$or $\mathrm{EC}^{+}$in transwells for 1 day before infection with a GFP reporter virus. On day 8 postinfection, infected cells were sorted for the GFP-negative fraction (which contains both uninfected and latently infected cells). GFP-negative cells were then cultured with or without PMA and Ionomycin (PMA/I) for 2 days. An integrase inhibitor raltegravir was included to prevent de novo virus integration. Since PMA/I is known to reactivate latent HIV, the increase of GFP-positive cells in T cells activated by PMA/I compared to $\mathrm{T}$ cells that are not activated by PMA/I is due to latently infected cells.

As shown in Figure 2, the increase in GFP expression in PMA/I-activated cultures (induced) compared with unactivated cultures (uninduced) was higher in $\mathrm{EC}^{-}$- and $\mathrm{EC}^{+}$stimulated $\mathrm{T}$ cells (in transwells), suggesting that soluble factors secreted by EC were able to induce latent infection in resting $\mathrm{CD}^{+} \mathrm{T}$ cells. In addition, the increase of GFP expression was greater in EC-stimulated resting $\mathrm{T}$ cells than that in $\mathrm{T}$ cells cultured alone (R). This result suggests that soluble factors secreted by EC were able to increase latent infection in resting $\mathrm{CD}^{+} \mathrm{T}$ cells. Finally, as was seen previously, ${ }^{22}$ no increase in GFP expression was seen in activated T cells upon PMA/I stimulation, indicating there were no latently infected cells.

\section{Early removal of $T$ cells from $E C$ resulted in reduced productive and latent infections}

One of the questions we were interested in investigating was how long the resting $\mathrm{T}$ cells needed to be stimulated by EC to achieve maximum infection. To set up the experiments, resting $\mathrm{CD}^{+} \mathrm{T}$ cells were isolated and cultured with $\mathrm{EC}(+/-)$ in direct contact or in transwell inserts (soluble factors only). After 1 day, the resting cells were infected with GFP reporter virus, and then they were removed from EC at various days postinfection and cultured separately. GFP expressions were measured on day 6 or 7 postinfection.

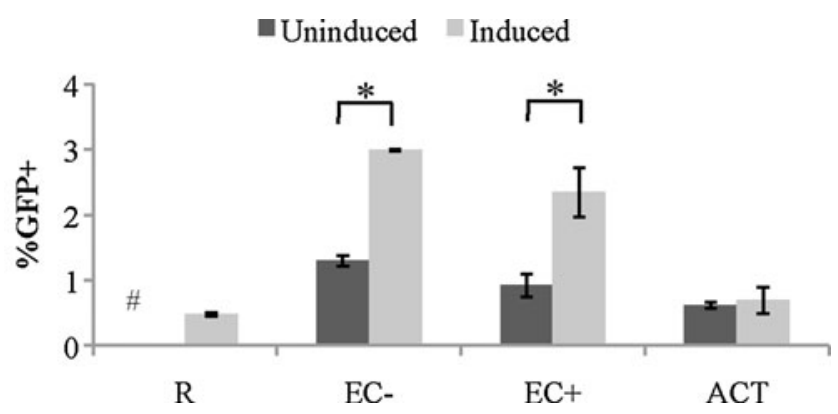

FIG. 2. Soluble factors secreted by EC can induce latent $\mathrm{HIV}$ infections in resting $\mathrm{CD} 4^{+} \mathrm{T}$ cells. Resting $\mathrm{CD} 4^{+} \mathrm{T}$ cells were cultured with or without EC in transwells and infected 1 day later with a GFP reporter virus. GFP-negative cells were sorted on day 8 postinfection and treated with or without PMA/ I to reactivate latent virus (labeled as induced and uninduced, respectively). GFP was measured 2 days after PMA/I treatment. Samples were taken in duplicates, and means \pm standard errors are plotted. Data shown are the representative of three independent experiments yielding similar results. *Student $t$-test; $p<.05$. ${ }^{\#}$ Uninduced resting T cells at $0 \%$. PMA, phorbol myristate acetate; PMA/I, PMA and Ionomoycin. 
We found that infection rates were higher the longer the resting $\mathrm{T}$ cells were allowed to be cocultured with $\mathrm{EC}$, in both direct contact settings (Fig. 3A) and in transwell settings (Fig. 3B). The maximal infection rates were achieved at day 5 postinfection, but not earlier. Moreover, while in the direct contact setting, $\mathrm{EC}^{+}$stimulation resulted in higher infection rates at all time points compared with $\mathrm{EC}^{-}$stimulation; in transwell settings, there was no difference between $\mathrm{EC}^{+}$and $\mathrm{EC}^{-}$stimulations at any time point (Fig. 3A, B). This suggests that similar soluble factors were again involved in both $\mathrm{EC}^{+}$ and $\mathrm{EC}^{-}$stimulations, whereas different cell surface molecules were involved in direct contact.

Finally, we investigated whether longer or shorter stimulation time between EC and T cells would result in more latent infection, as latent infection may require more or less stimulation than productive infection. To set up the experiments, resting $\mathrm{CD} 4^{+} \mathrm{T}$ cells were isolated and cultured with $\mathrm{EC}(+/-)$ in direct contact for 1 day before infection. On days 1 and 3 postinfection, one third of the T cells were removed from the coculture and cultured alone until day 8 postinfection. Then, GFP-negative cells were sorted out from each separate culture, and each cultured with or without PMA/I. GFP expressions were measured 2 days later.

As shown in Figure 3C, latent infection was observed for all stimulation times. For $\mathrm{EC}^{-}$stimulated cultures, removal at day 1 resulted in significantly less latent infection than at day 8 , but removal at day 3 was very similar or had even higher latent infection than removal at day 8 . For $\mathrm{EC}^{+}$cultures, all time points looked similar to one another. Altogether, these results suggest that the longer the stimulation between EC and $\mathrm{T}$ cells, the higher the infection rates. For productive infection, it may require up to 5 days of stimulation, whereas for latent infection, 1-3 days of stimulation seemed sufficient.

\section{ELISA multiplex assay suggests involvement of IL-6, IL-8, and CCL2}

To determine which EC soluble factors were involved in stimulating the resting $\mathrm{CD}^{+} \mathrm{T}$ cells, we decided to perform a multiplex ELISA. To prepare for the assay, resting $\mathrm{CD}^{+} \mathrm{T}$ cells were cultured alone or with $\mathrm{EC}^{+}$and $\mathrm{EC}^{-}$for 6 days and the supernatant was collected and frozen at $-80^{\circ} \mathrm{C}$. Supernatants collected from MCF7 cells (also cocultured with resting $\mathrm{CD}^{+} \mathrm{T}$ cells for 6 days) and resting $\mathrm{CD} 4^{+} \mathrm{T}$ cells cultured alone were used as negative controls. MCF7 stimulation does not induce $\mathrm{HIV}$ infection of resting $\mathrm{CD}^{+} \mathrm{T}$ cells. ${ }^{22}$ Culture supernatants from $\mathrm{EC}^{+}$and $\mathrm{EC}^{-}$cultured alone without $\mathrm{T}$ cells were also included in the analysis of IL-6.

After analyzing various cytokine data from the multiplex ELISA, we found that among the 30 cytokines we examined on the panel, IL-6, IL-8, and CCL2 levels had the most difference between the EC cocultures and the negative controls: resting $\mathrm{CD}^{+} \mathrm{T}$ cells alone or cocultured with MCF7 (Fig. 4). Compared to EC cultured alone, addition of $\mathrm{T}$ cells resulted in a slight increase of IL-6 secretion (Fig. 4A).

\section{IL-6 stimulation increases productive infection in resting $C D 4^{+} T$ cells}

After finding three candidate cytokines from the multiplex ELISA, we investigated the effect of these cytokines, IL-6, IL8 , and CCL2, on HIV infection of resting $\mathrm{CD}^{+} \mathrm{T}$ cells. Resting $\mathrm{CD}^{+} \mathrm{T}$ cells were isolated and incubated with
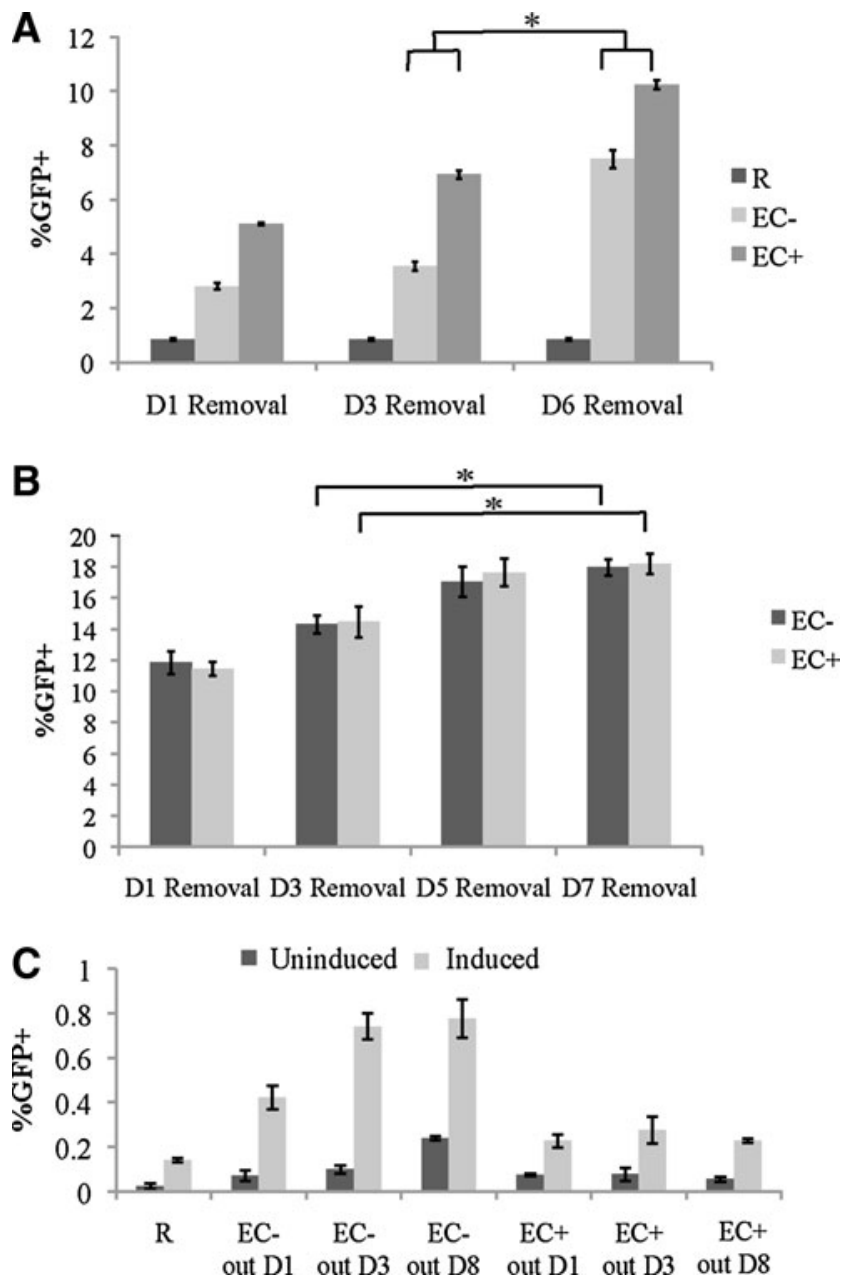

FIG. 3. Early removal of $\mathrm{T}$ cells from EC resulted in reduced productive and latent infections. (A) Early removal of resting $\mathrm{CD}^{+} \mathrm{T}$ cells stimulated by direct contact with EC. Resting $\mathrm{T}$ cells were cultured in contact with $\mathrm{EC}^{-}$or $\mathrm{EC}^{+}$, infected with a GFP reporter virus, and were removed at various time intervals after infection. The $\% \mathrm{GFP}^{+}$cells were measured on day 6 postinfection for all cultures, and the days that the resting $\mathrm{CD} 4^{+} \mathrm{T}$ cells were removed postinfection are as indicated. Samples were taken in triplicates, and means \pm standard errors are plotted. Data shown are the representative of three independent experiments yielding similar results. (B) Early removal of resting $\mathrm{CD}^{+}{ }^{+} \mathrm{T}$ cells stimulated by soluble factors with EC. Resting $\mathrm{CD}^{+}{ }^{+} \mathrm{T}$ cells were cultured with $\mathrm{EC}^{-}$or $\mathrm{EC}^{+}$in transwells, infected 1 day later with a GFP reporter virus, and removed at the indicated days postinfection. GFP expressions were measured on day 7 after infection. Samples were taken in quadruplicates, and means \pm standard errors are plotted. Data shown are the representative of four independent experiments yielding similar results. (C) Latent infection in early removal of resting $\mathrm{CD}^{+} \mathrm{T}$ cells from EC stimulation. Resting $\mathrm{CD}^{+} \mathrm{T}$ cells were cultured in direct contact with $\mathrm{EC}$, and on various days postinfection, a portion of cells were removed. On day 8 postinfection, GFP-negative cells were sorted and cultured with or without PMA/I (labeled as induced and uninduced, respectively) for 2 days to reactivate latent virus. Samples were taken in triplicates, and means \pm standard errors are plotted. Data shown are the representative of three independent experiments yielding similar results. ${ }^{*}$ Student $t$-test; $p<.05$. 

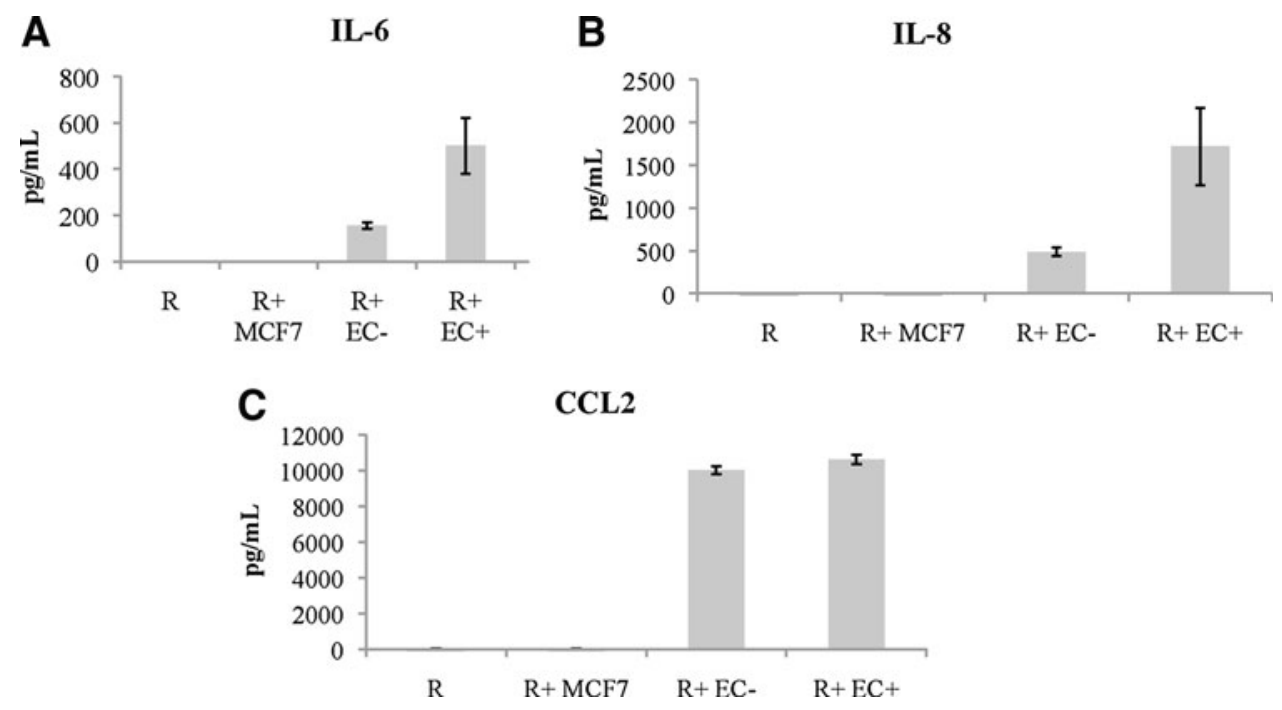

FIG. 4. Levels of IL-6, IL-8, and CCL2 in cultures of resting CD4 ${ }^{+} \mathrm{T}$ cells stimulated by EC. Resting CD4 ${ }^{+} \mathrm{T}$ cells were cultured alone, with $\mathrm{MCF} 7$, or with $\mathrm{EC}^{+} / \mathrm{EC}^{-}$for 6 days, and the supernatants were collected and analyzed for 30 cytokines. (A) IL-6 levels in resting T cells cultured alone or stimulated by EC. EC cultured alone were included as well. (B) IL-8 levels in resting $\mathrm{T}$ cells cultured alone, with MCF7 or stimulated by EC. (C) CCL2 levels in resting CD4 ${ }^{+}$T cells cultured alone, with MCF7 or stimulated by EC. Samples were averaged from two different donors each in duplicates, and means \pm standard errors are plotted.

recombinant human IL-6, IL-8, and CCL2 first at concentrations similar to those produced by EC cultures (as shown measured in Fig. 4) and later at several fold higher concentrations to ensure the potency of recombinant cytokines. After 1 day of incubation with the cytokines, the T cells were infected with a GFP reporter virus. The cells were incubated for 6 days, while the cytokine concentrations were refreshed every other day postinfection. The $\% \mathrm{GFP}^{+}$cells were measured on day 6 postinfection in each treatment.

As seen in Figure 5A, only treatment with IL-6 resulted in increased infection levels in resting $\mathrm{CD} 4^{+} \mathrm{T}$ cells, while IL-8 and CCL 2 had no effect. When we treated resting T cells with increasing concentrations of IL-6, infection rates in those cells were dose dependent (Fig. 5B). At the highest concentration of IL-6, the infection rate was very similar to that in $\mathrm{EC}^{-}$-stimulated T cells. When all three cytokines were added together to resting $\mathrm{T}$ cells, no increase of infection rates was detected beyond IL-6 stimulation alone (data not shown).

To confirm that IL- 6 was responsible for increased infection rates in EC-stimulated resting $\mathrm{CD} 4^{+} \mathrm{T}$ cells, we decided to block it with an anti-IL-6 antibody. ECs were plated and treated with an anti-human IL-6 antibody at three different concentrations of 10,5 , and $2 \mu \mathrm{g} / \mathrm{ml}$. Then, resting $\mathrm{T}$ cells were added to EC allowing for contact, but not allowing for IL-6 interaction. After 1 day, T cells stimulated by EC, with or without anti-IL-6 antibody or with an isotype control antibody, were infected and GFP levels were measured on day 6 postinfection.

As seen in Figure 5C, the addition of anti-IL-6 antibody at all three titration levels resulted in the same and significantly lower infection rates in resting cells stimulated by $\mathrm{EC}^{-}$and $\mathrm{EC}^{+}$. For some of the experiments, we also measured IL-6 levels using ELISA in IL-6 antibody blocking wells, and the free IL-6 levels in those wells were essentially zero (data not shown).

We also performed IL-6 antibody blocking experiments in transwell settings at the $10 \mu \mathrm{g} / \mathrm{ml}$ concentration, and the re- sults showed that EC stimulations were blocked by the antibody (Fig. 5D). In the case of resting cells stimulated by $\mathrm{EC}^{-}$, the addition of anti-IL-6 antibody reduced the infection rates to the level of unstimulated resting cells, suggesting that IL-6 was solely responsible for the effect of $\mathrm{EC}^{-}$stimulation in transwell. For $\mathrm{EC}^{+}$stimulation, however, addition of antiIL-6 antibody did not completely reduce the infection level to that of unstimulated resting cells, suggesting that for $\mathrm{EC}^{+}$ cells, soluble factors other than IL-6 were also involved in stimulation of resting $\mathrm{T}$ cells.

To confirm that IL-6 did not activate resting T cells while rendering resting $\mathrm{T}$ cells permissive for HIV infection, we measured the expression of activation markers in resting $\mathrm{T}$ cells on the day of infection, and 3 and 6 days postinfection. While there was significant increase of infection in IL-6stimulated cells on day 6 postinfection (right two bars), at any time point measured, no significant amount of activation markers was detected (Fig. 5E).

\section{IL-6, IL-8, or CCL2 treatments of resting $C D 4^{+}$ $T$ cells do not increase latent infection}

Once we confirmed that IL-6 induced productive infection in resting $\mathrm{CD}^{+} \mathrm{T}$ cells, while $\mathrm{IL}-8$ and CCL2 did not, we decided to investigate whether these cytokines would induce latent infection in resting $\mathrm{CD}^{+}{ }^{+} \mathrm{T}$ cells. Resting $\mathrm{T}$ cells were cultured alone or with IL-6 or CCL 2 for 1 day before infection with a GFP reporter virus. On day 8 postinfection, GFPnegative cells were sorted out and cultured alone or treated with PMA and Ionomycin and the integrase inhibitor raltegravir for 2 days. GFP expressions were compared between the induced group (treated with PMA/I) and the uninduced group (untreated) (Fig. 6A). Similarly, in a separate experiment, resting $\mathrm{T}$ cells cultured alone were compared with resting $\mathrm{T}$ cells stimulated by $\mathrm{EC}^{-}$in transwells, by IL-6 or IL8 (Fig. 6B). 

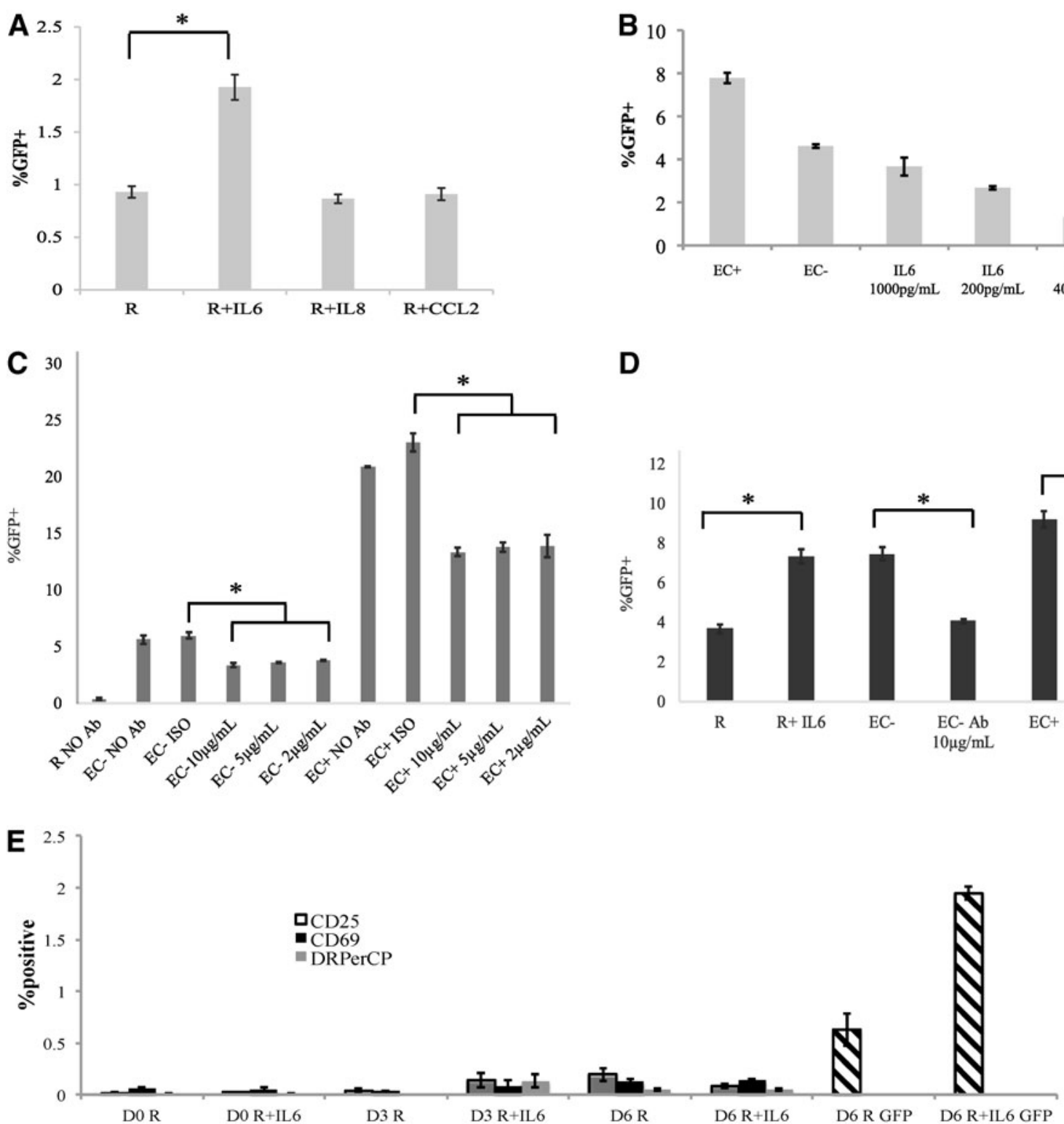

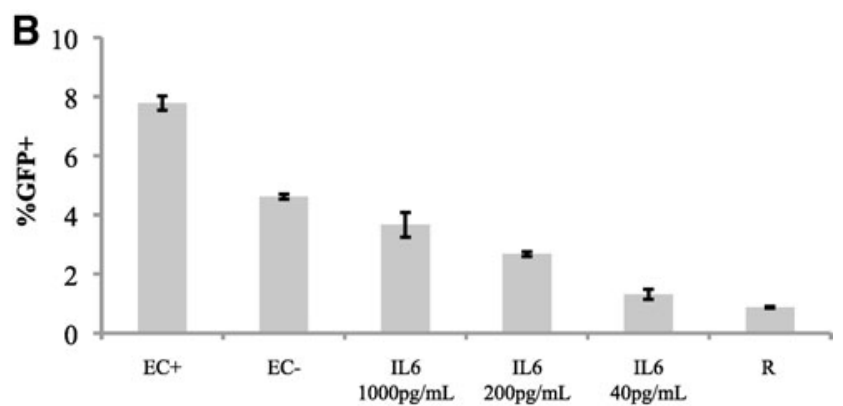

D

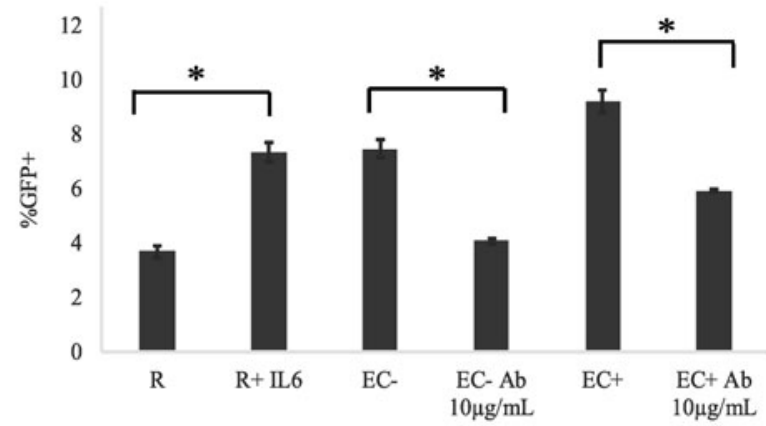

FIG. 5. IL-6 stimulation increases productive infection in resting $\mathrm{CD} 4^{+} \mathrm{T}$ cells without $\mathrm{T}$ cell activation. (A) Three different cytokines, IL-6, IL-8, and CCL2, were added to resting CD4 ${ }^{+}$T cells 1 day before infection with a virus expressing GFP. Cytokines were replenished every other day after infection, and GFP-positive rates were measured on day 7 postinfection. (B) IL-6 concentration is positively associated with infection rates. Resting T cells were cultured with various concentrations of IL-6 1 day before infection with a reporter virus. The cytokine was replenished on days 1,3 , and 5 postinfection, and GFP was measured on day 6 postinfection. Resting T cells alone and resting T cells cultured with $\mathrm{EC}^{-}$or EC ${ }^{+}$were used as controls. $(\mathbf{C})$ EC stimulation is blocked by anti-IL-6 antibody. An anti-IL6 antibody (Ab) was added to EC ${ }^{+/-}$for approximately an hour before addition of resting $\mathrm{T}$ cells in direct contact at three concentrations $(10,5$, and $2 \mu \mathrm{g} / \mathrm{ml})$. After culturing for a day, the cells were infected with a virus expressing GFP. The antibodies were refreshed on days 1 and 3 postinfection, and GFP levels were measured on day 6 postinfection. (D) Similar to the experiment in (C), except that T cells were cultured in transwell with EC. Antibody level was at $10 \mu \mathrm{g} / \mathrm{ml}$. Resting CD4 ${ }^{+} \mathrm{T}$ cells cultured alone or treated with IL-6 served as controls. (E) Lack of T cell activation by IL- 6 stimulation. Resting CD4 ${ }^{+}$T cells were cocultured with IL- 6 at $1 \mathrm{ng} / \mathrm{ml}$ for 1 day and then infected with a GFP reporter virus. CD25, CD69, and HLA-DR levels were measured on the day of infection (D0) and day 3 (D3) and 6 (D6) postinfection. The cytokine was replenished on days 1, 3, and 5 postinfection, and GFP was measured on day 6 postinfection (the right two bars). Samples were taken in triplicates, and means \pm standard errors are plotted. Data shown are the representative of at least three independent experiments yielding similar results. *Student $t$-test; $p<.05$.

Compared with resting cells alone, neither IL-6 nor CCL2 stimulations induced any additional latent infection, whereas IL-8 stimulation may have had slightly increased latent infection in comparison to resting cells alone, but it was much less than latent infection induced by $\mathrm{EC}^{-}$(in transwells).

\section{p-JNK, MURR1, and GLUT1 are not involved in EC stimulation}

To explore what cellular changes occur after the resting $\mathrm{T}$ cells were stimulated by EC, we examined various proteins 

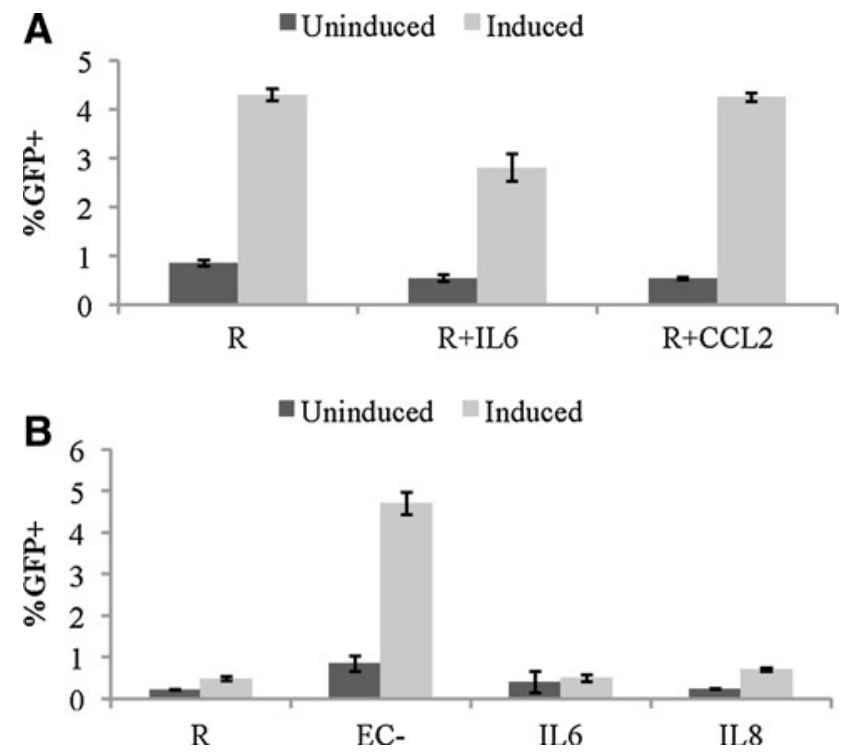

FIG. 6. IL-6, IL-8, and CCL 2 treatments do not increase latent infection. Resting cells were cultured with $\mathrm{EC}^{-}$, untreated, or treated with IL-6, IL-8, CCL2, and infected with a GFP reporter virus the next day. GFP-negative cells were sorted out on day 8 postinfection. Sorted cells were either uninduced or induced with PMA/I for 2 days before GFP analysis. (A) IL-6 and CCL2 do not induce latent infection more than resting alone. (B) IL-8 induces slightly more latency than resting alone and IL-6, but much less than EC $^{-}$ (through transwell)-stimulated resting cells. Samples were taken in quadruplicates, and means \pm standard errors are plotted. Data shown are the representative of two independent experiments yielding similar results.

that have been shown to affect HIV infection in resting CD4 ${ }^{+}$ T cells, ${ }^{23-25}$ namely JNK, MURR1, and GLUT1. We compared the expressions of these proteins in stimulated and unstimulated resting $\mathrm{CD}^{+}{ }^{+} \mathrm{T}$ cells.

Expression of JNK, or more precisely p-JNK, was shown to allow integration of HIV into the host cell genome. ${ }^{23}$ To compare p-JNK levels, we performed intracellular staining on resting $\mathrm{T}$ cells cultured alone, cocultured with $\mathrm{EC}^{+-}$, and activated with PMA/I (which are known to activate p-JNK), using primary and secondary antibodies. A sample stained only with the secondary antibodies was included as a nonspecific staining control for each treatment. As seen in Figure 7A, while activated T cells had significantly higher levels of p-JNK than resting $\mathrm{T}$ cells alone, $\mathrm{p}-\mathrm{JNK}$ expression was similar between resting $\mathrm{T}$ cells cultured alone and those stimulated with ECs, indicating that EC stimulation did not increase p-JNK levels.

To confirm the intracellular staining data, we performed a western blot on resting T cells cultured alone, cocultured with $\mathrm{EC}^{+-}$, and activated with PMA/I using a different antibody, JNK-FL. Similar results were observed: while activated T cells showed higher JNK levels, EC-stimulated T cells had similar levels of JNK as resting T cells alone (Fig. 7B).

Next, we examined whether infected $\mathrm{T}$ cells would have higher levels of p-JNK by comparing p-JNK levels in $\mathrm{GFP}^{+}$ (infected) cells and $\mathrm{GFP}^{-}$(uninfected) cells. Resting $\mathrm{T}$ cells cultured alone or cocultured with ECs were infected for 6 days, and $\mathrm{GFP}^{+}$and $\mathrm{GFP}^{-}$fractions of the cells were sorted out and p-JNK levels were measured through intracellular staining. As shown in Figure 7C, there was no difference in $\mathrm{p}-\mathrm{JNK}$ levels between $\mathrm{GFP}^{+}$and $\mathrm{GFP}^{-}$cells in any treatment group.

MURR1 was found to block HIV replication in resting T cells, ${ }^{24}$ so we expected to find a decrease of Murr1 in ECstimulated cells and low levels of MURR1 in infected cells. Therefore, we infected resting $\mathrm{T}$ cells cultured alone, cocultured with EC, and activated with PHA, which were sorted for GFP-positive and GFP-negative fractions 6 days postinfection, and then MURR1 levels were measured in each fraction. We found no decrease of Murr1 expression in ECstimulated resting $\mathrm{CD}^{+}{ }^{+} \mathrm{T}$ cells compared with resting $\mathrm{T}$ cells cultured alone (Fig. 7D). MURR1 levels were actually higher in $\mathrm{GFP}^{+}$(infected) cells than $\mathrm{GFP}^{-}$(uninfected) cells, showing that Murr1 expression did not hinder HIV infection.

Glut1 expression was found to correlate with HIV infection, ${ }^{25}$ so we infected resting $\mathrm{T}$ cells cultured alone, cocultured with EC, and activated with PHA, and then measured GLUT1 levels. As seen in Figure 7E, while activated T cells had significantly higher levels of GLUT1 than resting T cells alone, Glut1 expression was similar between resting $\mathrm{T}$ cells cultured alone and cocultured with ECs, indicating that EC stimulation did not significantly increase GLUT1 levels. Furthermore, the percentage of GFP-positive cells was much higher than the percentage of GLUT1-positive cells in either resting $\mathrm{T}$ cells cultured alone or EC-stimulated resting T cells, indicating that Glut1 expression did not correlate with HIV infection in resting $\mathrm{T}$ cells or resting $\mathrm{T}$ cells stimulated by $\mathrm{EC}$.

\section{Discussion}

In this study, we determined that direct cell-to-cell contact between $\mathrm{EC}$ and resting $\mathrm{CD} 4^{+} \mathrm{T}$ cells was not necessary to stimulate resting $\mathrm{T}$ cells, and a substantial amount of productive infection was achieved in transwell settings, which only allow for exchange of soluble factors between ECs and resting $\mathrm{T}$ cells (Fig. 1). However, infection rates were significantly higher in direct contact settings than in transwell settings; therefore, it is likely that both soluble factors and cell surface molecules played a role. This is further supported by the experiment illustrated in Figure 5C, where blockage of soluble factor IL- 6 in resting cells stimulated by $\mathrm{EC}^{+}$still resulted in significantly higher infection rates than those in resting $\mathrm{T}$ cells alone.

We also found that soluble factors from EC can induce higher levels of latent infection than those in resting $\mathrm{T}$ cells cultured alone (Fig. 2). These results suggest that in in vivo situations, resting $\mathrm{T}$ cells do not have to have physical contact with EC; rather, through soluble factors EC can render resting T cells permissive for productive and latent infection by HIV. If physical contact is indeed not required, larger numbers of resting $\mathrm{T}$ cells could be made infectible by $\mathrm{EC}$ than previously estimated.

We previously discovered that maximum levels of productive infection in EC-stimulated resting $\mathrm{T}$ cells were achieved at approximately 6-7 days postinfection. ${ }^{22}$ In this study, we set out to determine how long it took EC to completely stimulate resting $\mathrm{CD}^{+} \mathrm{T}$ cells to achieve the maximum amount of productive infection. We found that it was necessary to keep the resting cells exposed to EC until $\sim 5$ days postinfection (Fig. 3) to achieve the maximum amount of productive infection. For latent infection, it seemed to take at 


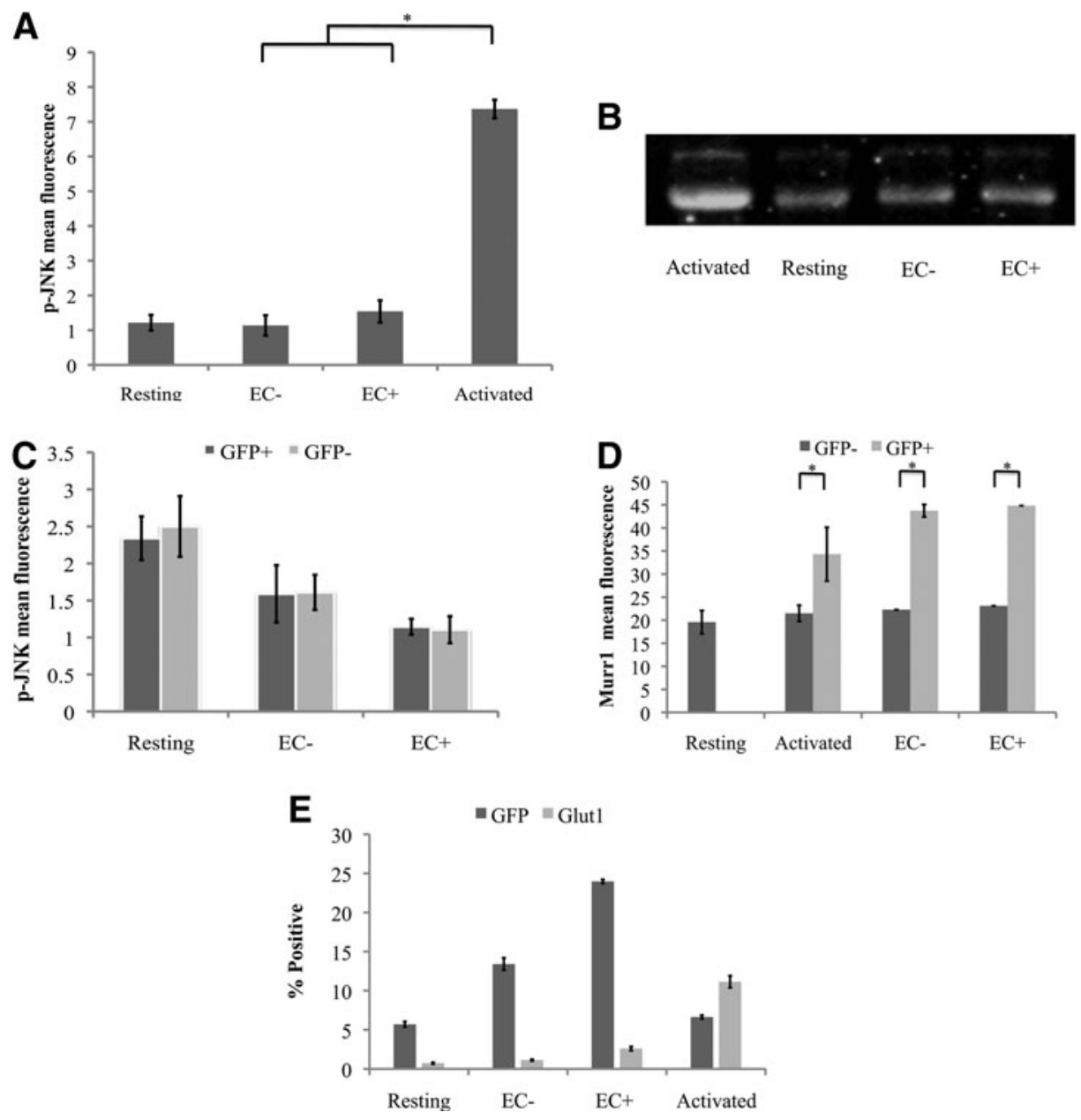

FIG. 7. JNK, Murr1, and Glut1 expression in resting T cells does not change after stimulation by EC. (A) Resting T cells were cultured alone, with $\mathrm{EC}^{+/-}$, or with PMA and Ionomycin. p-JNK intracellular staining was done 4 days later for PMA/Iactivated cells, and 7 days later for resting T cells cultured alone or with $\mathrm{EC}^{-}$and $\mathrm{EC}^{+}$. Samples were taken in duplicates, and means \pm standard deviations are plotted. Data shown are the representative of two independent experiments yielding similar results. (B) In a similar way, resting $\mathrm{CD}^{+}{ }^{\mathrm{T}}$ cells were cultured alone, activated with PMA/I, or cocultured with $\mathrm{EC}^{-}$or $\mathrm{EC}^{+}$ and analyzed for JNK expression through western blot analysis. (C) Resting CD4 ${ }^{+} \mathrm{T}$ cells were cultured alone or with EC $\mathrm{C}^{-}$ $\mathrm{EC}^{+}$and infected with a GFP reporter virus the next day. Intracellular staining was done on day 7 postinfection to measure pJNK expression. GFP ${ }^{+}$cells were productively infected, and $\mathrm{GFP}^{-}$cells were not productively infected. Samples were taken in

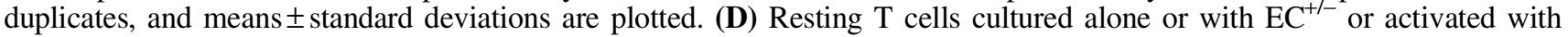
PMA/I. Murr1 expression was determined by intracellular staining 7 days after infection. Samples were taken in duplicates, and means \pm standard deviations are plotted. Data shown are the representative of two independent experiments yielding similar results. (E) Resting CD4 ${ }^{+} \mathrm{T}$ cells were cultured alone, activated by PHA, or stimulated by $\mathrm{EC}^{+/-}$. Cells were infected with a GFP reporter virus. GFP expression and GLUT1 staining were performed 3 days after infection for PHA-activated cells and 7 days after infection for resting cells that were unstimulated or stimulated by EC. Samples were taken in triplicates, and means \pm standard errors are plotted. Data shown are the representative of three independent experiments yielding similar results. *Student t-test; $p<.05$. Glut1, glucose transporter 1; JNK, c-Jun N-terminal kinase; PHA, phytohemagglutinin; p-JNK, phosphorylated JNK.

least 3 days. These results showed that the longer the contact with $\mathrm{T}$ cells, either through direct contact or through soluble factors, the more effect EC has on T cells. Since the maximum effect takes a few days to achieve, there is a wider window for therapeutic intervention.

Next, we investigated which soluble factor or factors were responsible for EC stimulation of resting $\mathrm{T}$ cells. We found a few candidate cytokines and chemokines that were at higher levels in EC-stimulated resting $\mathrm{T}$ cell cultures, and among them we found IL- 6 to be the culprit. IL-6 can definitively induce higher levels of productive infection in resting T cells, almost to the level of $\mathrm{EC}^{-}$stimulation in transwells (Fig. 5D).
When IL-6 is blocked by an antibody, the effect of EC ${ }^{-}$ stimulation was reduced in direct contact and almost obliterated in transwells (Fig. 5C, D). These results showed that IL- 6 was secreted by EC to render resting T cells permissive for productive HIV infection. Moreover, just as ECs did not activate resting $\mathrm{T}$ cells, ${ }^{22}$ with the level we tested in vitro, resting $\mathrm{T}$ cells were not activated by IL-6 stimulation (Fig. 5E).

IL-6 is a proinflammatory cytokine commonly found in elevated levels in HIV patients. ${ }^{26-28}$ In addition, ECs are not the only cells secreting IL-6 in vivo; many cell types, including fibroblasts, monocytes/macrophages, and even 
$\mathrm{T}$ cells, produce them when stimulated. ${ }^{29,30}$ The discovery that IL-6 renders resting T cells permissive for HIV infection could explain why so many resting T cells are infected in HIV patients in vivo. ${ }^{31}$

IL-6 was found to induce productive HIV infection of resting $\mathrm{CD}^{+} \mathrm{T}$ cells, but not latent infection (Fig. 6). The other two soluble factors that were at higher levels in stimulated T cell cultures, IL-8 and CCL2, were also not responsible for inducing latent infection.

Many cytokines have been previously identified to be involved in inducing latent HIV infection, including CCL19, CCL21, IL-7, and IL-15. ${ }^{32,33}$ In our last study, we investigated their potential involvement in EC stimulation of resting T cells and found none of them was involved. ${ }^{22}$ In this study, more specifically in the multiplex ELISA experiment, we eliminated many cytokines on the multiplex panel, but we have not yet found the cytokine or cytokines that were secreted by EC to induce latent HIV infection in resting T cells. Our plan for the next study is to do an RNA-seq experiment to investigate which cytokines or chemokines are differentially expressed in EC compared with those in resting T cells or in MCF7. Once we identify candidate genes, we will perform the latency assay to investigate their involvement.

In the last part of this study, we turned our attention to the changes that would take place within resting $\mathrm{T}$ cells after EC stimulation. To investigate which intracellular molecules might be allowing productive HIV infection in EC-stimulated resting $\mathrm{CD}^{+} \mathrm{T}$ cells, we examined three different proteins that were known to have an effect on HIV infection in resting T cells.

Murr1 was previously thought to inhibit HIV-1 infection, ${ }^{23}$ but we found this was not the case. Cells infected by the virus $\left(\mathrm{GFP}^{+}\right)$showed higher expression of Murrl than those that were not infected by the virus $\left(\mathrm{GFP}^{-}\right)$, which shows that MURR1 cannot inhibit HIV-1 infection in T cells (Fig. 7D). Furthermore, we found that the resting $\mathrm{T}$ cells stimulated by EC had similar levels of MURR1 to the resting cells that were not stimulated by ECs, meaning that Murrl expression did not change after T cell stimulation by EC (Fig. 7D). Actually, we found activated $\mathrm{CD} 4^{+} \mathrm{T}$ cells had similar or slightly higher levels of MURR1 than resting $\mathrm{T}$ cells (data not shown). Therefore, MURR1 did not seem to be involved in restricting HIV infection of resting T cells.

Two other proteins we investigated were p-JNK and GLUT1, which were thought to positively affect HIV infection in $\mathrm{CD}^{+} \mathrm{T}$ cells. Loisel-Meyer et al. showed that increased levels of GLUT1 allowed for more productive infection of HIV. We found this to be true with our activated and resting $\mathrm{CD}^{+} \mathrm{T}$ cells, but it was not significant in the resting $\mathrm{T}$ cells stimulated by $\mathrm{EC}$, since their expression of Glut1 was similar to resting populations (Fig. 7E).

Manganaro et al. showed that high JNK expression allows for productive HIV-1 infection, and we confirmed this by measuring p-JNK and JNK levels in our activated and resting $\mathrm{CD}^{+} \mathrm{T}$ cell populations (Fig. $7 \mathrm{~A}-\mathrm{C}$ ). The resting $\mathrm{T}$ cells stimulated by EC had similar levels of p-JNK to the resting $\mathrm{CD} 4^{+} \mathrm{T}$ cells; therefore, $\mathrm{p}-\mathrm{JNK}$ was not a factor in allowing higher HIV-1 infection rates in EC-stimulated resting cells.

Since all of the proteins previously explored do not allow for productive HIV-1 infection in resting $\mathrm{CD}^{+} \mathrm{T}$ cells stimulated by EC, more extensive investigations need to be done. Messenger RNA (mRNA) sequencing can be used to compare resting $\mathrm{T}$ cells before and after stimulation by $\mathrm{EC}$, allowing us to see which genes are differentially expressed after EC stimulation. Discovering the factor(s) that are responsible for HIV infection of resting T cells intracellularly is important because it will allow us to block them, thus preventing infection of resting $\mathrm{CD} 4^{+} \mathrm{T}$ cells in vivo and the formation of latent viral reservoirs. Our plan for the next study is to do RNA-seq experiment to compare gene expressions in resting $\mathrm{T}$ cells cultured alone and those in ECstimulated resting $\mathrm{T}$ cells.

Overall, we demonstrated that soluble factors secreted by ECs can induce productive and latent HIV infections in resting $\mathrm{CD} 4^{+} \mathrm{T}$ cells, although infection rates were higher with physical contact from EC. We further characterized the interactions between EC and T cells with regard to the length of contact, cytokines involved, and intracellular factors. We found that IL- 6 secreted by EC is responsible for inducing productive infection in resting $\mathrm{T}$ cells, but not for latent infection. From our previous work ${ }^{22}$ and the multiplex cytokine ELISA we did in this study, we found that many cytokines known to be involved in inducing latent infection in resting $\mathrm{T}$ cells, such as CCL19, CCL21, IL-7, or IL-15, were not involved in EC stimulation of resting $\mathrm{T}$ cells.

These results suggest that new and unidentified soluble factors are involved, and further work is needed to identify them. In addition, intracellular factors previously identified to be involved in allowing HIV infection of resting $\mathrm{T}$ cells were not involved in EC stimulation, which suggests yet another new mechanism exists that allows HIV infection of resting $\mathrm{T}$ cells.

\section{Acknowledgments}

The authors thank the late Dr. Jiangmei Yin, who performed the Multiplex Cytokine ELISA and who contributed to the Materials and Methods section of the article concerning the assay (may she rest in peace). They also thank Mary Dekker, Annie Barron, Valerie Joy (Yu) Tan, Seth Verkaik, Noah Praamsma, and Jared Doezema for excellent technical assistance; Drs. Lin Shen, Shan Liang, Jason Dinoso, and Sifei Xing for providing plasmids, virus, and cells; Lori Keen for managerial assistance; and the blood donors for their generosity. This study was supported by Calvin College and NIH (grant AI096991 to A.S.). The funders had no role in study design, data collection, and interpretation, or the decision to submit the work for publication.

\section{Author Disclosure Statement}

No competing financial interests exist.

\section{References}

1. Pierson T, McArthur J, Siliciano RF: Reservoirs for HIV-1 mechanisms for viral persistence in the presence of antiviral immune responses and antiretroviral therapy. Annu Rev Immunol 2000;18:665-708.

2. Turriziani O, Andreoni M, Antonelli G: Resistant viral variants in cellular reservoirs of human immunodeficiency virus infection. Clin Microbiol Infect 2010;16:1518-1524.

3. Rezaei SD, Cameron PU: Human immunodeficiency virus (HIV)-1 integration sites in viral latency. Curr HIV/AIDS Rep 2015;12:88-96.

4. Spina CA, Anderson J, Archin NM, et al:: An in-depth comparison of latent HIV-1 reactivation in multiple cell 
model systems and resting $\mathrm{CD} 4^{+} \mathrm{T}$ cells from aviremic patients. PLoS Pathog 2013;9:e1003834.

5. Korin YD, Zack JA: Progression to the G1b phase of the cell cycle is required for completion of human immunodeficiency virus type 1 reverse transcription in T cells. $\mathrm{J}$ Virol 1998;72:3161-3168.

6. Spina CA, Guatelli JC, Richman DD: Establishment of a stable, inducible form of human immunodeficiency virus type 1 DNA in quiescent CD4 lymphocytes in vitro. J Virol 1995;69:2977-2988.

7. Stevenson M, Stanwick TL, Dempsey MP, Lamonica CA: HIV-1 replication is controlled at the level of T cell activation and proviral integration. EMBO J 1990;9:15511560.

8. Zack JA, Arrigo SJ, Weitsman SR, et al.: HIV-1 entry into quiescent primary lymphocytes: Molecular analysis reveals a labile, latent viral structure. Cell 1990;61:213-222.

9. Zack JA, Haislip AM, Krogstad P, Chen IS: Incompletely reverse-transcribed human immunodeficiency virus type 1 genomes in quiescent cells can function as intermediates in the retroviral life cycle. J Virol 1992;66:1717-1725.

10. Pierson TC, Zhou Y, Kieffer TL, et al.: Molecular characterization of preintegration latency in human immunodeficiency virus type 1 infection. J Virol 2002;76: 8518-8531.

11. Zhou Y, Zhang H, Siliciano JD, Siliciano RF: Kinetics of human immunodeficiency virus type 1 decay following entry into resting $\mathrm{CD}^{+}{ }^{+} \mathrm{T}$ cells. J Virol 2005;79:2199-2210.

12. Eckstein DA, Penn ML, Orin YDK, et al.: HIV-1 actively replicates in naive CD4(+) $\mathrm{T}$ cells residing within human lymphoid tissues. Immunity 2001;15:671-682.

13. Li Q, Duan L, Estes JD, et al.: Peak SIV replication in resting memory $\mathrm{CD}^{+} \mathrm{T}$ cells depletes gut lamina propria $\mathrm{CD}^{+} \mathrm{T}$ cells. Nature 2005;434:1148-1152.

14. Nishimura Y, Brown CR, Mattapallil JJ, et al.: Resting naive $\mathrm{CD}^{+} \mathrm{T}$ cells are massively infected and eliminated by X4-tropic simian-human immunodeficiency viruses in macaques. Proc Natl Acad Sci U S A 2005;102:8000-8005.

15. Ostrowski MA, Chun TW, Justement SJ, et al.: Both memory and CD45RA+/CD62L+ naive CD4(+) T cells are infected in human immunodeficiency virus type 1-infected individuals. J Virol 1999;73:6430-6435.

16. Wightman F, Solomon A, Khoury G, et al.: Both CD31(+) and CD31 naive CD4(+) T cells are persistent HIV type 1 infected reservoirs in individuals receiving antiretroviral therapy. J Infect Dis 2010;202:1738-1748.

17. Brenchley JM, Hill BJ, Ambrozak DR, et al.: T-cell subsets that harbor human immunodeficiency virus (HIV) in vivo: Implications for HIV pathogenesis. J Virol 2004;78:1160-1168.

18. Kreisberg JF, Yonemoto W, Greene WC: Endogenous factors enhance HIV infection of tissue naive CD4 T cells by stimulating high molecular mass APOBEC $3 \mathrm{G}$ complex formation. J Exp Med 2006;203:865-870.

19. Kinter A, Moorthy A, Jackson R, Fauci AS: Productive HIV infection of resting $\mathrm{CD}^{+}{ }^{+} \mathrm{T}$ cells: Role of lymphoid tissue microenvironment and effect of immunomodulating agents. AIDS Res Hum Retroviruses 2003;19:847-856.

20. Choi J, Walker J, Boichuk S, Kirkiles-Smith N, et al: Human endothelial cells enhance human immunodeficiency virus type 1 replication in $\mathrm{CD} 4^{+} \mathrm{T}$ cells in a Nef-dependent manner in vitro and in vivo. J Virol 2005;79:264-276.

21. Choi J, Walker J, Talbert-Slagle K, Wright P, Pober JS, Alexander L: Endothelial cells promote human immunodeficiency virus replication in nondividing memory $\mathrm{T}$ cells via Nef-, Vpr-, and T-cell receptor-dependent activation of NFAT. J Virol 2005;79:11194-11204.

22. Shen A, Baker JJ, Scott GL, Davis YP, Ho YY, Siliciano RF: Endothelial cell stimulation overcomes restriction and promotes productive and latent HIV-1 infection of resting CD4 $^{+}$T cells. J Virol 2013;87:9768-9779.

23. Manganaro L, Lusic M, Gutierrez MI, Ceresto A, Del Sal G, Giacca M: Concerted action of cellular JNK and Pin1 restricts HIV-1 genome integration to activated $\mathrm{CD}^{+}{ }^{+} \mathrm{T}$ lymphocytes. Nat Med 2010;16:329-334.

24. Ganesh L, Burstein E, Guha-Niyogi A, et al.: The gene product Murr1 restricts $\mathrm{HIV}-1$ replication in resting $\mathrm{CD}^{+}$ lymphocytes. Nature 2003;236:853-857.

25. Loisel-Meyer S, Swainson L, Craveiro M, et al.: Glut1mediated glucose transport regulates HIV infection. Proc Natl Acad Sci U S A 2012;109:2549-2554.

26. Breen EC, Rezai AR, Nakajima K, et al.: Infection with HIV is associated with elevated IL-6 levels and production. J Immunol 1990;144:480-484.

27. Ullum H, Diamant M, Victor J, et al.: Increased circulating levels of interleukin-6 in HIV-seropositive subjects. J Acquir Immune Defic Syndr Hum Retrovirol 1996;13:93-94.

28. Vera Tudela E, Singh MK, Lagman M, et al.: Cytokine levels in plasma samples of individuals with HIV infection. Austin J Clin Immunol 2014;1:1003.

29. Venketaraman V, Morris D, Donohou C, et al:: Role of cytokines and chemokines in HIV infection. In: Updates on Biology, Immunology, Epidemiology and Treatment Strategies (Dumais N, ed.) In Tech, 2011. Pp. 286-287.

30. Kamimura D, Ishihara K, Hirano T: IL-6 signal transduction and its physiological roles: The signal orchestration model. Rev Physiol Biochem Pharmacol 2003;149:1-38.

31. Zhang ZQ, Schuler T, Zupancic M, et al.: Sexual transmission and propagation of SIV and HIV in resting and activated CD4 ${ }^{+}$T cells. Science 1999;286:1353-1357.

32. Saleh S, Solomon A, Wightman F, Xhilaga M, Cameron PU, Lewin SR: CCR7 ligands CCL19 and CCL21 increase permissiveness of resting memory $\mathrm{CD}^{+} \mathrm{T}$ cells to HIV -1 infection: A novel model of HIV-1 latency. Blood 2007;110: 4161-4164.

33. Unutmaz D, KewalRamani VN, Marmon S, Littman DR: Cytokine signals are sufficient for HIV-1 infection of resting human T lymphocytes. J Exp Med 1999;189:1735-1746.

Address correspondence to: Anding Shen

Department of Biology Calvin College

1726 Knollcrest Circle SE Grand Rapids Michigan 49546

E-mail: as28@calvin.edu 